\title{
Thanatophoric dysplasia- a rare cause of stillbirth and perinatal mortality: a case report
}

\author{
Priti Agrawal $^{1 *}$, Rishi Agrawal ${ }^{2}$, Anandi Lobo ${ }^{3}$
}

\begin{abstract}
${ }^{1}$ Department of Obstetrics, Gynecology and Infertility, ${ }^{2}$ Department of General and Laparoscopic Surgery, ${ }^{3}$ Department of Pathology, Aarogya Hospital and Test Tube Baby Center, Raipur, Chhattisgarh, India
\end{abstract}

Received: 07 January 2021

Revised: 10 February 2021

Accepted: 11 February 2021

\author{
*Correspondence: \\ Dr. Priti Agrawal, \\ E-mail: drpritiagrawal15@gmail.com
}

Copyright: () the author(s), publisher and licensee Medip Academy. This is an open-access article distributed under the terms of the Creative Commons Attribution Non-Commercial License, which permits unrestricted non-commercial use, distribution, and reproduction in any medium, provided the original work is properly cited.

\begin{abstract}
Lethal skeletal dysplasia is estimated to occur in 0.95 per 10,000 deliveries. Thanatophoric dysplasia affects about 1 in 25000 to 50000 births. The term thanatophoric is Greek word for "death bearing". Children with this condition are usually stillborn or die shortly after birth from respiratory failure. We report a case of LSD (Thanatophoric dysplasia), in an unbooked patient where previous two children and couple were absolutely normal. Our patient, 31 years old, unbooked case presented with history of amenorrhea 8 months and unable to perceive fetal movements. Her husband's age was 33 years. This was her third pregnancy. She had previous 2 deliveries by LSCS. Ultrasonography revealed single intrauterine live fetus in breech presentation with multiple fetal anomalies. There was shortening and deformity of all four limbs (micromelia) with poor mineralization of all bones. Thorax was pear shaped with short horizontal ribs and abnormal cardiothoracic ratio. LSCS was done in emergency for impending rupture of previous LSCS scar. Post-delivery examination and X-ray of the fetus revealed decreased skull mineralization, frontal bossing, hypoplastic nasal bone, midface hypoplasia, mandibular hypoplasia, pear shaped chest, protuberant abdomen, micromelia, dumbbell shaped appearance of all long bones. TD is caused due to mutation of the fibroblast growth factor receptor 3 gene (FGFR3), which is located on the short arm of chromosome 4. Type I TD is characterized by marked underdeveloped skeleton and short-curved long bones. Conventional radiographic examination remains the most useful means of studying the dysplastic skeleton. Bony evaluation is best done on X-rays or ultrasonography. The diagnosis of TD can be established with ultrasound and molecular confirmation in the second trimester can help in genetic counselling and termination of such lethal pregnancies. LSD's are rare event. If our patient had undergone anomaly scan in second trimester of pregnancy, this defect could have been detected earlier. The outcome of fetus is lethal but maternal morbidity can be reduced if diagnosed early.
\end{abstract}

Keywords: Skeletal dysplasia, Thanatophoric dysplasia, FGFR3, Ultrasound

\section{INTRODUCTION}

Skeletal dysplasia (SD) are a heterogeneous group of inheritable disorders characterized by abnormalities of cartilage and bone growth, resulting in abnormal shape and size of the skeleton and dipropionate growth of long bones, spine, and head, also known as osteochondro dysplasia.
Commonly seen SD include achondroplasia, osteogenesis imperfecta, thanatophoric dysplasia (TD), campomelic dysplasia, and hypochondroplasia.

SD account for $5 \%$ of all congenital anomalies. The overall incidence of SD is approximately 1 case per 4000-5000 births. Lethal skeletal dysplasia's (LSD) are estimated to occur in 0.95 per 10,000 deliveries. TD and achondroplasia account for $62 \%$ of all LSD. TD is rare 
with incidence of 1 in 25000 to 50000 births. $^{1}$ Among infants with SD detected at birth, approximately $13 \%$ are stillborn, and $44 \%$ die during the perinatal period.

The term thanatophoric is Greek word for "death bearing". Children with this condition are usually stillborn or die shortly after birth from respiratory failure. We report a case of LSD (Thanatophoric dysplasia), in an unbooked patient where previous two children and couple were absolutely normal.TD was diagnosed on the basis of ultrasonography and post-delivery examination and $\mathrm{X}$ ray, of the fetus.

\section{CASE REPORT}

Our patient, 31 years old, unbooked case presented with history of amenorrhea 8 months and unable to perceive fetal movements. Her husband's age was 33 years. This was her third pregnancy. She had previous 2 deliveries by LSCS. First daughter was eight years old with normal growth pattern and intelligence. Second daughter was four years old and normal. Both deliveries were done by LSCS for breech presentation. In the present pregnancy she was unaware of the pregnant status for initial five months and she had not taken any medication. In her antenatal visit she very specifically mentioned that she felt that there is some solid lump in her abdomen and there were no fetal movements which she could appreciate during her previous 2 pregnancies. There was no event of abortion or still birth. The couple was normal phenotypically. It was not a consanguineous marriage. These was no history of dwarfism, mental retardation or any congenital anomalies in the maternal or paternal families. On physical examination of patient, height was $158 \mathrm{~cm}$, weight-70 kilograms, BMI- 28.04 with normal intelligence, vitals were stable. Husband's height was 170 cms, weight-75 kgs, BMI-25.95 with normal intelligence. The couple was postgraduate and belonged to rural area. On per abdomen examination, pfannestiel scar was seen, uterine fundal height was about 34 weeks, large for date, (by LMP-30 weeks) polyhydramnios with breech presentation with normal fetal heart sounds, previous LSCS scar was non-tender. Routine blood investigations were within normal limits.

Ultrasonography revealed single intrauterine live fetus in breech presentation with multiple fetal anomalies. There was shortening and deformity of all four limbs (micromelia) with poor mineralization of all bones. Head showed macrocephaly with depressed nasal bridge, hypoplastic nasal bone, hypoplastic cerebellum, mild subdural fluid with frontal bossing (Figure 1A). Thorax was pear shaped with short horizontal ribs and abnormal cardiothoracic ratio. Abdomen was protuberant with mild ascites (Figure 1B). Hands had very short phalanges with trident shape (Figure 1C). Umbilical cord cyst was noted (Figure 2A). There was polyhydramnios with AFI-23 (Figure 2B). Middle cerebral artery flow was normal (Figure 2C).

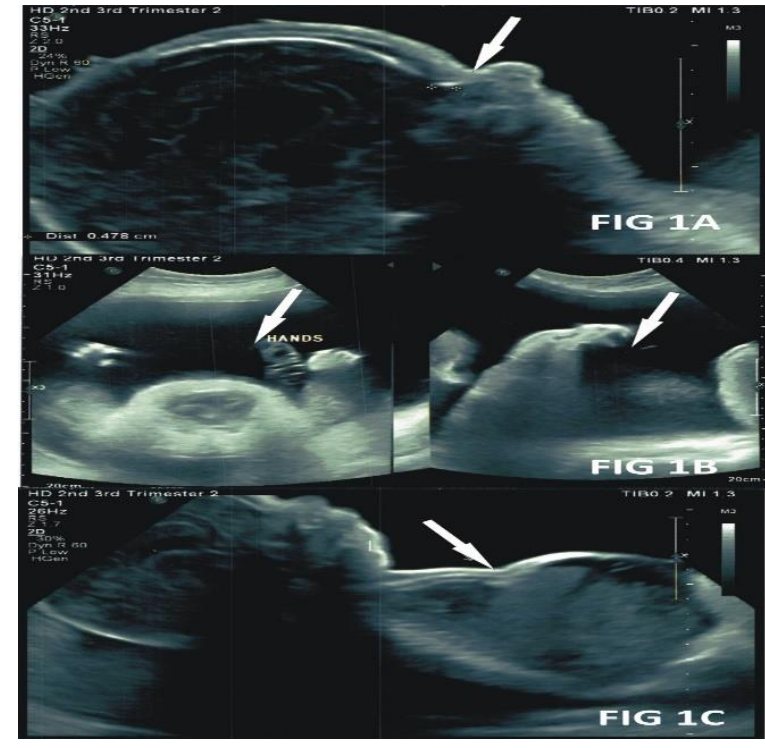

Figure 1: (A) Macrocephalic head significant frontal bossing depressed nasal root short nasal tip (B) micromelia, trident hand $(C)$ Pear shaped chest with short ribs protuberant abdomen.

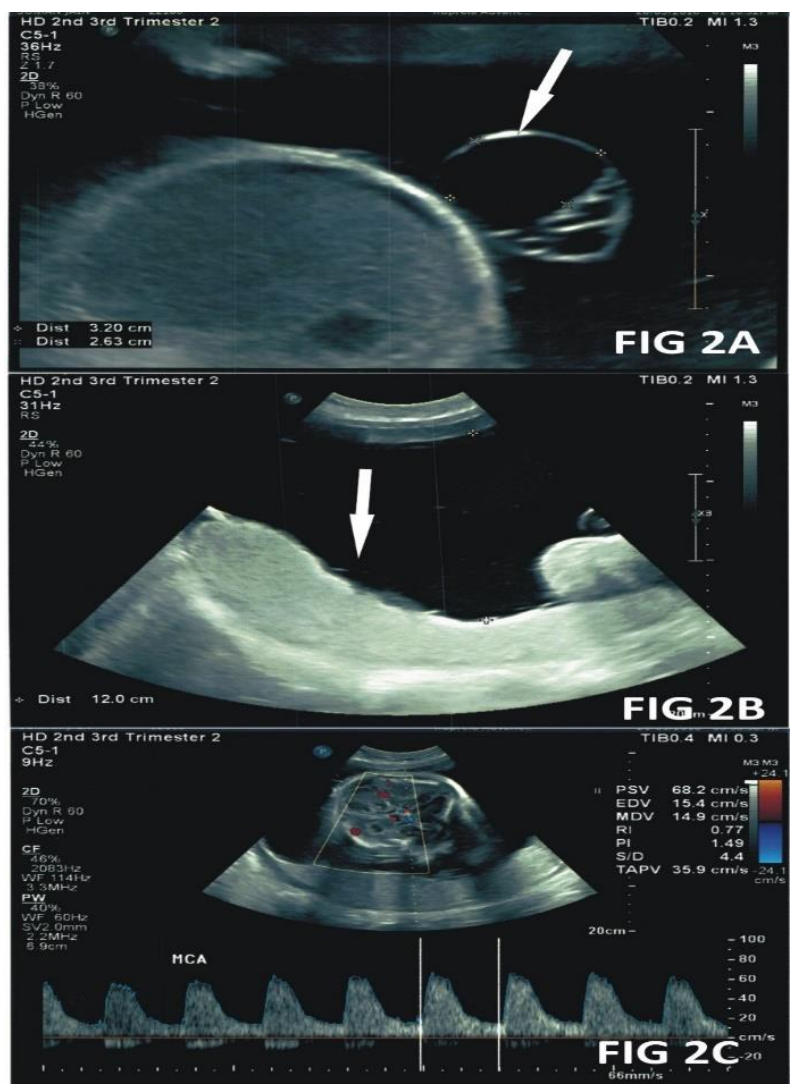

Figure 2: (A) umblical cord cyst (B) polyhydramnios AFI-23 (C) middle cerebral artery flow normal.

Thorough counselling of the couple was done, LSCS was done in emergency for impending rupture of previous LSCS scar. Baby was delivered with difficulty as tissue's were friable, heart rate was about 60/minute with gasping respiration and baby died after 10 minutes of birth. 
Placenta was highly friable and come out in piecemeal. Remaining intra and post-operative period was uneventful for the patient.

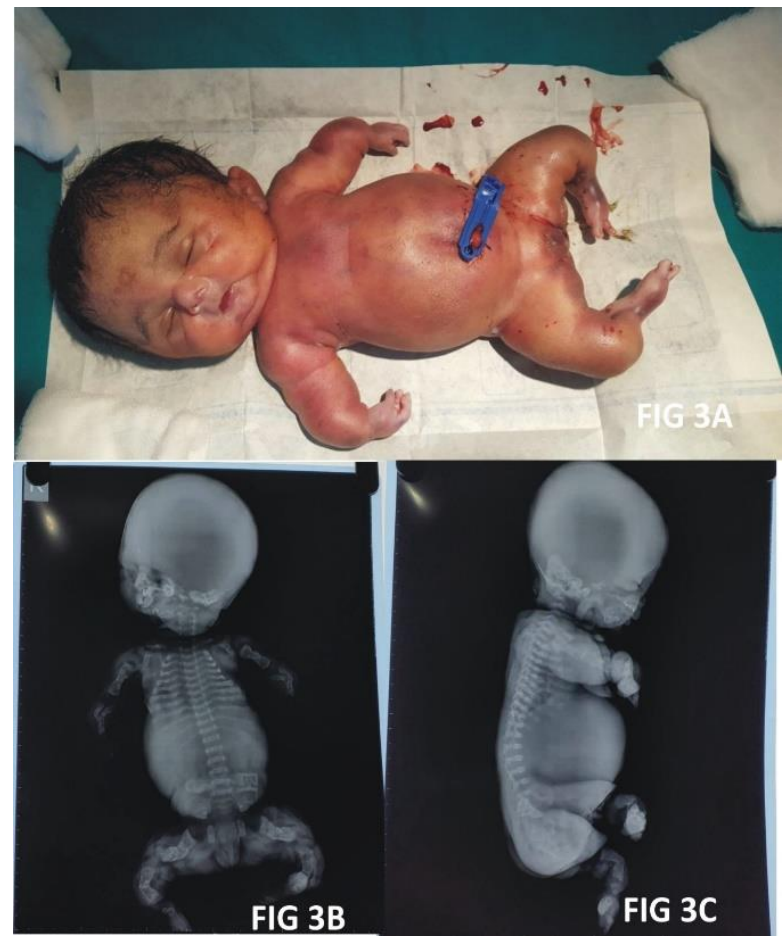

Figure 3: (A) Thantotrophic dysplasia in the fetus of 32 weeks gestational age $(B)$ micromelia, dumbbell shaped appearance of all long bones (C) Poor mineralization of vertebrae, flattened spinal bones (Platyspondyly), increased intervertebral space.

Post-delivery examination (Figure 3A) and X-ray of the fetus revealed decreased skull mineralization, frontal bossing, hypoplastic nasal bone, midface hypoplasia, mandibular hypoplasia, pear shaped chest, protuberant abdomen, micromelia, dumbbell shaped appearance of all long bones (Figure 3B), bowing of limbs (campomelic), 90-degree attachment of all limbs to the trunk, poor mineralization of vertebrae, flattened spinal bones (Platyspondyly), increased intervertebral space abnormal morphology of the pelvis, including small squared iliac wings, narrowed sacro sciatic notch, flat acetabular roof and extra skin on the arms and legs (Figure 3C). Parents refused post-mortem and further genetic analysis of the fetus as they had two healthy children and also opted for vasectomy in future.

\section{DISCUSSION}

The 2015 revision of Nosologyand Classification of Genetic Skeletal Disorders recognizes 436 genetic skeletal diseases, stemming from mutations in 364 genes, with the disorders organized into 42 groups. ${ }^{2-5}$

Skeletal dysplasia can be inherited as autosomal dominant, autosomal recessive, X-linked, or Y-linked. Examples include 1) autosomal dominant - fibroblast growth factor 3 (FGFR3) disorders (achondroplasia, 6 thanatophoric dysplasia, hypochondroplasia) and type II collagen disorders (achondrogenesis II, spondyloepiphyseal dysplasia congenita, Kniest dysplasia) 2) autosomal recessive-cartilage-hair hypoplasia, Ellis-van Creveld syndrome, hypophosphatasia, osteopetrosis 3) X-linked dominant chondrodysplasia punctata (CDP) 4) X-linked recessive Conradi- Hunermann CDP.

TD is caused due to mutation of the fibroblast growth factor receptor 3 gene (FGFR3), which is located on the short arm of chromosome 4 . The mutation results in the activation of FGFR3 tyrosine kinase independently of ligands such as fibroblast growth factor. ${ }^{8}$ This activation of FGFR3 results in decreased apoptosis and increased proliferation. It was reported that hypochondroplasia, achondroplasia and thanatophoric dysplasia are the different types of mutation in FGFR3 with hypochondroplasia being the mildest and TD, the most severe form. Type I TD is characterized by marked underdeveloped skeleton and short-curved long bones. The pelvic bones and vertebral columns are underdeveloped, cloverleaf skull may or may not be present. ${ }^{6}$ In type II TD, the long bones are not as short as in type I and are not bent. The fetuses with type II TD are reported to have cloverleaf skull which means a trilobed skull.

Anthropometric parameters should be compared with the gestational age for the newborn or the chronologic age of the patient, considering appropriate racial, ethnic, socioeconomic, and perinatal factors. Conventional radiographic examination remains the most useful means of studying the dysplastic skeleton. Bony evaluation is best done on X-rays or ultrasonography.

Recently, noninvasive ultrasonography has gained acceptance in diagnosing fetal skeletal dysplasia. which has a sensitivity of about $60 \%$ Three-dimensional ultrasonography 7 has been reported to have a somewhat better sensitivity compared with 2D ultrasonography and to be particularly useful for the evaluation of facial dysmorphism and anomalies involving the hands and feet. ${ }^{7}$ If a newborn has been diagnosed with a known lethal disorder in the fetal period, then treating physicians should offer comfort care for the newborn, but not aggressive management. Defining lethality in the prenatal period can be accomplished by two means; molecular diagnosis of a known lethal disorder, precise diagnosis by ultrasound or chest size abnormalities seen by ultrasound that correlate with lethality. If the chest to abdominal circumference ratio is less than. ${ }^{7}$ The heart to chest circumference is $>50$ percent or the abdomen to femur length ratio is $<0.16$, these objective measures are highly correlated with lethality. ${ }^{8}$

Correct diagnosis allows proper genetic counseling and outcome of the fetus. Since the majority of cases of TD occur sporadically, it is important to counsel that the 
recurrence risk is low for only one previously affected fetus and that the entire group of family member are not at increased risk. ${ }^{9}$ Avoidance of consanguineous marriages may further reduce the risk of transmission. Naveen et al reported TD in a couple who had first degree consanguineous marriage and there was no past or family history of congenital abnormalities. ${ }^{10}$

The diagnosis of TD can be established with ultrasound and molecular confirmation in the second trimester can help in genetic counselling and termination of such lethal pregnancies. $^{11}$

\section{CONCLUSION}

LSD's are rare event. If our patient had undergone anomaly scan in second trimester of pregnancy, this defect could have been detected early. The outcome of fetus is lethal but maternal morbidity can be reduced if diagnosed early. Routine anomaly scan can easily diagnose SD and lethal variants can be offered early termination of pregnancies.

Funding: No funding sources Conflict of interest: None declared Ethical approval: Not required

\section{REFERENCES}

1. Miller E, Blaser S, Shannon P, Widjaja E. Brain and bone abnormalities of thanatophoric dwarfism. AJR Am J Roentgenol 2009;192(1):48-51.

2. Bonafe L, Cormier-Daire V, Hall C, Lachman R, Mortier G, Mundlos S, et al. LNosology and classification of genetic skeletal disorders: 2015 revision. Am J Med Genet A. 2015;167A(12):286992.
3. Hopyan S, Gokgoz N, Poon R, Gensure RC, Yu C, Cole WG. A mutant PTH/PTHrP type I receptor in enchondromatosis. Nat Genet. 2002;30(3):306-10.

4. Alman BA. Skeletal dysplasias and the growth plate. Clin Genet. 2008;73(1):24-30.

5. Chen C, Jiang Y, Xu C, Liu X, Hu L, Xiang Y, et al. Skeleton Genetics: a comprehensive database for genes and mutations related to genetic skeletal disorders. Database (Oxford). 2016.

6. McDonald EJ, De Jesus O. Achondroplasia. Stat Pearls. 2020.

7. Krakow D, Williams J 3rd, Poehl M, Rimoin DL, Platt LD. Use of three-dimensional ultrasound imaging in the diagnosis of prenatal-onset skeletal dysplasias. Ultrasound Obstet Gynecol. 2003;21(5):467-72.

8. Krakow D. Skeletal Dysplasias. Clin Perinatol. 2015;42(2):301-19.

9. Lam AC, Lam YY, Tong TM, Chan DK, Lau WL, Ng DK, Ho CS, Chan K, Lam ST, Thanatophoric dysplasia type 1 (TD1) without "telephone receivers". HK J Paediatr. 2006;11:320-3.

10. Naveen NS, Murlimanju BV, Kumar V, Pulakunta T. Thanatophoric dysplasia: a rare entity. Oman Medic J. 2011;26(3):196.

11. Wong HS, Kidd A, Zuccollo J, Tuohy J, Strand L, Tait J, et al. A case of thanatophoric dysplasia: the early prenatal $2 \mathrm{D}$ and $3 \mathrm{D}$ sonographic findings and molecular confirmation of diagnosis. Fetal Diagn Ther. 2008;24(1):71-3.

Cite this article as: Agrawal P, Agrawal R, Lobo A. Thanatophoric dysplasia- a rare cause of stillbirth and perinatal mortality: a case report. Int J Reprod Contracept Obstet Gynecol 2021;10:1232-5. 